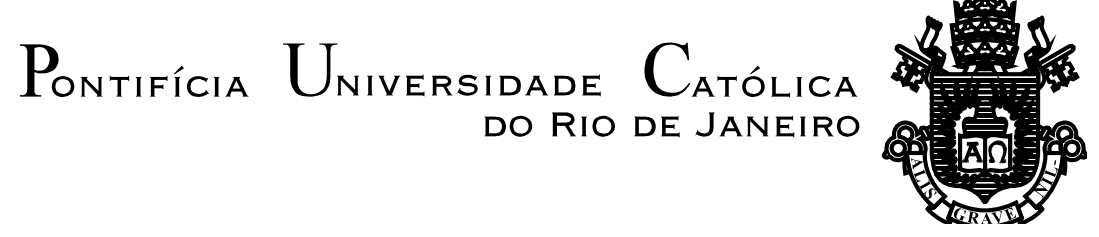

Marta de Mattos Vieira Barcellos Costa

\title{
A oficina de escrita como lugar de (re)criação e inserção literária
}

Dissertação de Mestrado

Dissertação apresentada ao Programa de Pós-graduação em Letras da PUC-Rio como requisito parcial para obtenção do título de Mestre em Literatura, Cultura e Contemporaneidade.

Orientadores: Prof. Ana Paula Veiga Kiffer Prof. Paulo Henriques Britto 
Pontifícia Universidade Catálica

\title{
MARTA DE MATTOS V BARCELLOS COSTA \\ A oficina de escrita como lugar de (re)criação e inserção literária
}

\begin{abstract}
Dissertação apresentada como requisito parcial para obtenção do grau de Mestre pelo Programa de Pós-Graduação em Literatura, Cultura e Contemporaneidade do Departamento de Letras do Centro de Teologia e Ciências Humanas da PUC-Rio. Aprovada pela Comissão Examinadora abaixo assinada.
\end{abstract}

\author{
Prof. Paulo Fernando Henriques Britto \\ Orientador \\ Departamento de Letras - PUC-Rio
}

Profa. Ana Paula Veiga Kiffer

Co-Orientador

Departamento de Letras - PUC-Rio

Profa. Marilia Rothier Cardoso

Departamento de Letras - PUC-Rio

Profa. Laura Rabelo Erber

UNIRIO

Profa. Denise Berruezo Portinari

Coordenadora Setorial do Centro de Teologia

e Ciências Humanas - PUC-Rio

Rio de Janeiro, 11 de abril de 2014. 
Todos os direitos reservados. É proibida a reprodução total ou parcial do trabalho sem autorização da universidade, da autora e dos orientadores.

Marta de Mattos Vieira Barcellos Costa

Marta Barcellos graduou-se em jornalismo pela Universidade Federal do Rio de Janeiro (UFRJ) em 1987. Especializou-se em Literatura, Arte e Pensamento Contemporâneo na CCE/PUC-Rio em 2011. Como jornalista, trabalhou nos jornais $\mathrm{O}$ Globo, Gazeta Mercantil e Valor Econômico - onde continua atuando como colaboradora do caderno EU\&Fim de Semana. É colunista da revista Capital Aberto, responsável pela seção Retrato, dedicada a biografias; e cronista do site Digestivo Cultural. Publicou três livros jornalísticos, além de dois contos na coletânea Sábado na estação (Ed.Apicuri), organizada por Luiz Ruffato.

Ficha Catalográfica

Costa, Marta de Mattos V. Barcellos

A oficina de escrita como lugar de (re)criação e inserção literária / Marta de Mattos V. Barcellos Costa ; orientador: Paulo Fernando Henriques Britto ; co-orientadora: Ana Paula Veiga Kiffer. - 2014.

$83 \mathrm{f.} ; 30 \mathrm{~cm}$

Dissertação (mestrado)-Pontifícia Universidade Católica do Rio de Janeiro, Departamento de Letras, 2014. Inclui bibliografia

1. Letras - Teses. 2. Oficina literária. 3. Construção da escrita. 4. Voz própria. 5. Vida literária. 6. Profissionalização do escritor. I. Britto, Paulo Fernando Henriques. II. Kiffer, Ana Paula Veiga. III. Pontifícia Universidade Católica do Rio de Janeiro. Departamento de Letras. IV. Título. 


\section{Agradecimentos}

Ao José Luiz Schaefer e à Ana Luísa Barcellos Schaefer Aos meus orientadores

Aos meus amigos

Aos meus professores no mestrado e na especialização

À Fátima Barroso

Ao João Paulo Vaz

À Cláudia Lage, ao Jair Ferreira dos Santos e ao Luiz Ruffato 


\section{Resumo}

Costa, Marta de Mattos V. Barcellos; Britto, Paulo Fernando Henriques; Kiffer, Ana Paula Veiga. A oficina de escrita como lugar de (re)criação e inserção literária. Rio de Janeiro, 2014. 83p. Dissertação de Mestrado - Departamento de Letras, Pontifícia Universidade Católica do Rio de Janeiro.

A partir da experiência da autora como participante em três oficinas de prosa de ficção, esta dissertação desenvolve reflexões sobre os caminhos da experimentação e da construção da escrita artística, e também da profissionalização do escritor. Da motivação do escrever às formas de inserção no sistema literário, a oficina se oferece em seus temas e dinâmicas como espaço de investigação das tensões relacionadas à prática da escrita na contemporaneidade: fundada sob o princípio do aprendizado, ela pressupõe o apagamento do autor como sujeito inspirado e original, mas convive com as ideias românticas em torno da criação. Embora aceitem os novos termos da intertextualidade e da aprendizagem técnica, seus alunos buscam uma "voz própria" e vivenciam a experiência da impessoalidade que escapa ao controle no processo de escrita. Neste trabalho, as atividades da oficina são apresentadas em diálogo com as noções barthesianas e deleuzeanas sobre a escrita, sua motivação e sua construção.

\section{Palavras-chave}

Oficina literária; construção da escrita; voz própria; vida literária; profissionalização do escritor. 


\section{Abstract}

Costa, Marta de Mattos V. Barcellos; Britto, Paulo Fernando Henriques (Advisor); Kiffer, Ana Paula Veiga (Co-Advisor). The writing workshop as a place of (re)creation and literary insertion. Rio de Janeiro, 2014. 83p. MSc. Dissertation - Departamento de Letras, Pontifícia Universidade Católica do Rio de Janeiro.

Considering the author's experience as a participant in three prose fiction's workshop, this dissertation develops reflections on the experimentation and construction ways of artistic writing and also on the writer's professionalism. From the writing motivation to the forms of insertion in the literary system, the workshop presents their themes and dynamics as a space to investigate the tensions related to the writing practice in contemporary times: based on the principle of learning, it requires the author's extinguishment as an inspired and original subject, but has a close association with romantic ideas around the creation. Although new terms of intertextuality and technical learning are accepted, the students search for a own voice and live the impersonality experience that goes beyond the control in the writing process. In this work, the workshop activities are presented in dialogue with the Barthes's and Deleuze's notions about writing, their motivation and construction.

\section{Keywords}

Literary workshop; writing construction; own voice; literary life; writer's professionalism. 


\section{Sumário}

1. Os contos 9

1.1. "Contra-dança" 9

1.2. "Planta circular" 13

1.3. "Do avesso" 16

1.4. "He or she" 19

2. Oficina uma narrativa 23

3. O querer-escrever 30

4. Do querer ao escrever: a dinâmica da oficina 41

4.1. A inserção no campo literário 45

4.2. Escrita que circula: os primeiros leitores 47

5. (Re)criação 51

5.1. Transbordamentos 55

5.2. A técnica (ou a trapaça) 66

5.3. Voz própria 73

6. Considerações finais 78

7. Referências bibliográficas $\quad 80$ 
Maintenant c'est écrit. C'est ce genre de dérapage-là peutêtre - je n'aime pas ce mot - très sombre, que l'on risque d'encourir. Ce n'est pas grave mais c'est un événement à lui seul, total, d'un sens énorme : d'un sens inaccessible et d'une étendue sans limites.

Marguerite Duras, Écrire 